\title{
Research on Multidimensional Cultivation of College English Learning Strategies under the Condition of Information Technology in Application Oriented Universities
}

\author{
Jie Xiao ${ }^{1, a}$, Weimin $\mathrm{Qi}^{2, \mathrm{~b}}$ \\ ${ }^{1}$ Department of Foreign Languages, Wenhua College, Wuhan 430070, China \\ ${ }^{2}$ School of Physics \& Information Engineering, Jianghan University, Wuhan 430056, China \\ aLuckycrystalxj@163.com, bqwmin@126.com
}

Keywords: English learning strategies; information technology; application oriented universities.

\begin{abstract}
Currently the college English learning is time-consuming and inefficient, which has caused extensive concern. A considerable number of the students thirst for improving English learning skills, but suffer from a lack of appropriate English learning strategies, which leads to high input and low output of the learning efficiency. Continuously for a long time, this kind of learning way will not only seriously frustrate the enthusiasm of the students, but also will be no conducive to promote students to develop the consciously lifelong learning habit, and will be no conducive to personal development. The advance of English curriculum reform inspires educators to think about the following question: how to teach students appropriate learning methods so that students can truly achieve the state of learning freely. In order to solve this practical problem, this research explores how to use O'Malley and Chamot's theory of learning strategies and Oxford's Strategy Inventory for Language Learning (SILL) as the means of measurement to cultivate the multidimensional college English learning strategies to students, especially to the students in application oriented universities. Different from other relevant research, this research combines with information technology used in college English teaching, aims to help college students, the students in application oriented universities in particular, master effective learning methods and learning strategies, learn how to conduct effective English learning, and harvest more fruits of learning based on enhancing the efficiency and quality of learning.
\end{abstract}

\section{Introduction}

Combining with information technology used in college English teaching, this research explores how to use relevant theory to cultivate the multidimensional college English learning strategies to students, especially to the students in application oriented universities. This research aims to help college students master effective learning methods and learning strategies, learn how to conduct effective English learning, and harvest more fruits of learning based on enhancing the efficiency and quality of learning. From a long term point of view, this research contributes to enhancing students' learning methods. It also has important theoretical and practical significance for the college students to establish lifelong consciousness of English learning.

\section{Relevant Research at Home and Abroad}

The research of English learning strategies began in 1970s, which mainly focused on the following 5 aspects: (1) learning strategies for students with English high score; (2) differences of strategies between high score and low score students in English learning; (3) the correlation of using strategies and language achievement; (4) the influence factors of using English learning strategies; (5)the training of English learning strategies.

In China, The study of English learning strategies began in the 1980's. In 1984 scholar Huang Xiaohua completed the master thesis with the title” An Investigation of Learning Strategies in Oral Communication that Chinese EFL Learners in China Employ" which marked the beginning of the study of learning strategies in China[1]. Wu Yi'an studied the influence of learning strategies on English achievement, taking the undergraduates as the research objects [2]. In 1990, Wen Qiufang, a 
scholar, conducted a questionnaire survey on college students' English learning strategies, and made a qualitative and quantitative research on the use of learning beliefs and learning strategies. In 1996 she published the book "the Theory of English Learning Strategies"[3]. In 2002, Wu Benhu, a scholar, made a new classification of English learning strategies based on the information processing learning theory [4].

Taking O'Malley and Chamot's theory of learning strategies [5, 6, 7] as a framework, using Oxford's Strategy Inventory for Language Learning (SILL) as the means of measurement, and taking the integration of information technology and college English teaching as an educational background, this research intends to make the freshmen in Wenhua College as the experimental object. This study intends to strengthen the teachers' knowledge update, to achieve the goal of scientific, systematic and the times of the learning strategy training. Students should be trained to master effective learning methods and learning strategies, to learn how to conduct efficient English learning, and to gain more learning achievements based on improving learning efficiency and quality.

\section{Research Objects and Contents}

It is necessary to define the following three concepts at first: information technology used in college English teaching, college students in application oriented universities, and multidimensional cultivation of college English learning strategies under the condition of information technology.

Information technology used in college English teaching: Based on computer network as the core, it combines the information technology with college English teaching, which has the characteristics of the stereoscopic teaching material, the networked teaching resources, virtualized teaching environment, personalized teaching, and procedural teaching evaluation.

College students in application oriented universities: it refers to the freshmen of non-English majors in application oriented universities. These groups of students are chosen as the research object for the following reasons: for one reason, most freshmen still use learning strategies learnt in high school, with mechanical memory and repetition as the main features. Their learning strategies and learning mode are still in the transition period and have the strongest plasticity. For the other, taking the national college entrance examination as the standard, the reliability and validity of this research are uniform and reliable, and this can be regarded as the original starting point of experimental data.

Multidimensional cultivation of college English learning strategies under the condition of information technology: taking O'Malley and Chamot's theory of learning strategies as a framework, using Oxford's Strategy Inventory for Language Learning( SILL) as the means of measurement, the multidimensional cultivation of English learning strategies should be infiltrated into the classroom teaching and extracurricular counseling, into the face-to-face teaching in group and individual counseling; and combining the explicit training with implicit training, employing lectures, theme activities, group activities, online counseling, the cultivation of English learning strategies should be melted into the teaching activities. This aims to make full use of information technology, promote the consciousness of students' learning strategies, expand the scope of their choice of learning strategies and use areas, and cultivate their self-monitoring ability of learning. In this way students can improve their efficiency and quality of English learning on the basis of the flexible control of learning strategies.

\subsection{Oxford's Learning Strategy Scale (SILL).}

This research uses the Oxford's learning strategy scale (SILL) as the measurement tool to investigate the college students' current using status and effect of English learning strategies under the condition of information technology.

Through questionnaire and interview, this research investigates the different levels of college students' using and effect of English learning strategies. The design of the questionnaire mainly refers to the Oxford learning strategy scale (Inventory for Language Learning Strategy, SILL) and uses the Likert five scale questionnaires, including memory strategy, cognitive strategy, compensation strategy, met cognitive strategy, affective strategy and social strategy. 
The purposes of this survey are as follows:

1. Determine the necessity of strategy training. By comparing the survey results, this research verifies whether the use of learning strategies by the students in application colleges is limited, and whether there is the need for the implementation of strategy training.

2. By comparing the differences of learning strategies between high and low score students, the research explores the characteristics and problems of the use of learning strategies by the low group students, studies how the different use of learning strategies affects the learning effect and helps low group students consciously improve learning methods.

3. Determine the principles of learning strategy training. The following principles should be followed: only training students the learning strategies which are not often used can make this experiment realistic and practical; only training students the learning strategies which are often used by high score but not the low score group of students is worthy to be promoted to all learners.

For the collected data, this research uses the means of statistical analysis to study the following two aspects of the problem: macroscopically, this research examines the present using status of the students' English learning strategies under the condition of information, including (1) the overall using level of the English learning strategies; (2)students' preferences in choosing strategies; (3)the using range of strategies. Microscopically, respectively from the point of view of memory strategy, cognitive strategy, compensation strategy, Meta cognitive strategy, affective strategy, social strategy, this research analyzes the using level of strategies and the results. According to the results, the cause of the problem is explored from the double perspective of teachers and students.

\subsection{Train the Learning Strategies to the Experimental Teachers.}

Experimental teachers' awareness of learning strategies, the use of learning strategies, the content and the implementation steps of strategy training, etc. directly affect the effectiveness of the students' strategy training experience. Therefore, teachers should strengthen the research activities in the teaching process, so that teachers can understand accurately the nature of the training, master the basic principles of the training, and improve the ability to implement the training.

The following questions should be discussed jointly by the experimental teachers and the researcher before the learning strategies are taught:(1) how to select the appropriate strategies in different learning strategies; (2) how to combine strategy instruction with different task based teaching; (3)teachers should use mother tongue or the second language in learning strategy training; (4) how to guide students to use learning strategies; (5) how to evaluate students' strategic choice;(6)how to sum up the status of students' strategy using, and how to promote the successful use of learning strategies.

\subsection{Theoretical Framework of Training Mode}

Take O'Malley and Chamot's "meta cognitive strategy, cognitive strategy, social / affective strategy "as the theoretical framework to explore the training mode of college English learning strategies under the condition of information technology. Chamot has proposed six steps of learning strategy training: (1)teachers evaluate students' strategy use level; (2)teachers put forward new learning strategies, and guide students to evaluate the strategies; (3)students acquire and practice the new strategies to achieve the degree of independent application; (4)students evaluate the use of the new strategies; (5)guide students to expand the application scope of the new strategies to other learning tasks; (6)teachers evaluate students' learning strategies.[5]

Combining the current teaching with the Chamot's ideas, this research builds a four-step training mode.

Step 1: Preparation stage--- focusing on the training of met cognitive learning strategy. In this stage, teachers mainly enable students to establish their learning strategy awareness, to promote students to reflect on their own learning strategies and understand the characteristics of language learning, and to establish a sense of learning strategies. At the same time, teachers can also learn more about the students' potential and cognitive characteristics to adjust the teaching methods and learning strategies in a timely manner. Also teachers can use the campus network platform and upload the relative teaching resources in the form of courseware or documents for students to learn independently. In this 
process teachers should emphasize the importance of strategy training, deepen the awareness that learning strategies can be learned and mastered, make students realize that the purpose of learning strategy training is to enable students to combine their own characteristics with flexible use of these strategies to form their own unique and efficient way of learning.

Step 2: Teaching stage---focusing on the training of cognitive strategy. Meta cognitive strategy can help students plan and manage self-learning and cognitive strategy can help students understand, digest and use the specific knowledge. In this phase, teachers can adopt the teaching mode of "seminar combining with classroom teaching, classroom teachers' teaching combining with self-access learning, and group learning combining with campus network learning".

In this process, teaching can be divided into the following 4 sub-steps:

1. Teachers choose learning strategies suitable for the students training. A number of factors will affect the strategy training, such as time, teaching methods, conditions, level of teachers, the needs and the acceptance ability of the audience etc. Therefore, the researcher need to consider comprehensively what strategies should be trained.

2. Teachers prepare teaching materials and design strategy training activities. Teachers can combine ordinary classroom teaching with learning strategy teaching to make the strategy training and textbook learning harmoniously together. This way also can make students learn more effectively and have more passion for learning.

3. Teachers explain the characteristics of the strategy, and demonstrate the purpose and usage through examples. Teachers use examples to demonstrate the beauty of using strategies, so that students can really feel the advantage and the learning gains. Therefore students consciously establish a sense of strategy use. After class, teachers can classify the training auxiliary materials according to the degree of difficulty and upload them to the school network platform for students' autonomous learning.

4. Students practice strategies. Teachers can use textbooks or extracurricular learning materials to design learning tasks, so that students can put the strategies into the real English learning. In this process teachers also should monitor and guide the students to practice. At the same time, teachers can use the school network platform to share the resources to achieve the purpose of strengthening the students' learning.

Step 3: Effect feedback of the learning strategy training and evaluation---focusing on the training of Meta cognitive strategy and social affective strategy. In this stage, the web-based autonomous learning platform and the formative assessment should be combined. On the one hand, the grading test system, online learning records, performance analysis and evaluation system of the network platform can make the students reflect on their own strategies. On the other hand, students can make self-training on the shared learning tasks, and then they can make self-evaluation, peer assessment, group evaluation, and teacher evaluation.

Step 4: Summary of the using learning strategies and the development phase: focusing on the training of cognitive and meta cognitive strategies. In this process, through the close contact with students teachers can collect students' classic cases of using learning strategies and upload these cases to the school's network platform in order to achieve full sharing of learning resources among students. Through the summary and development of learning strategies, teachers can help students manage their self-learning better, and ensure the motivation and methods of students' lifelong foreign language learning.

The overall research ideas of this subject are shown in Fig.1.

\section{Conclusion}

The research on the multidimensional cultivation of college English learning strategies under the condition of information technology in application oriented universities can not only make full use of the teaching facilities brought by the information technology, but also can help college students grasp appropriate learning strategies and solve learning difficulties due to lack of learning strategies. 
Developing the learning strategy training program suitable for the students' self-development and the potential specialty is also in line with the individualized and personalized teaching philosophy of education.

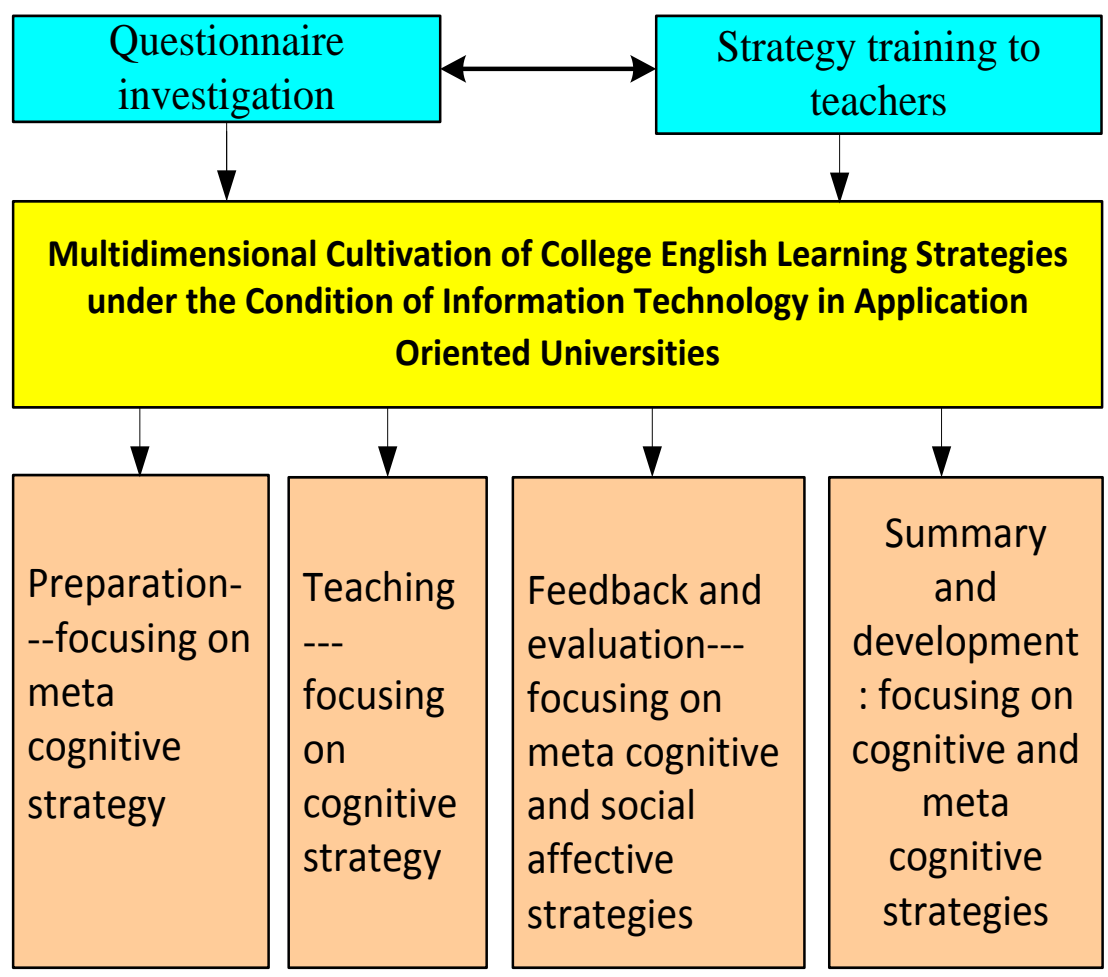

Fig. 1 Multidimensional cultivation of English learning strategies mode

\section{Acknowledgment}

This research was financially supported by the 12th Five-Year Educational and Scientific Planning Project of Hubei Provincial Department of education, 2014 (Grant NO. 2014B311).

\section{References}

[1]. Huang, Xiao-hua, "An investigation of learning strategies in oral communication that Chinese EFL learners in China employ”. Chinese university in Hong Kong: Unpublished M. A. thesis. 1984.

[2]. Wu Yian.Liu Runqing, P. Jeffery. “An Investigation Report on the Quality of Chinese English Majors”. Journal of English Teaching and Research, Jan 1993.

[3]. Wen Qiufang. “The Theory of English Learning Strategies”, Shanghai English Education Press, 1996.

[4]. Wu Benhu, “English Learning Strategies”. Anhui Education Press, pp.10-11, 2002.

[5]. A. U. Chamot, "Language learning strategy instruction: current issues and research", Annual Review of Applied Linguistics, vol. 25, pp. 112-130, 2005.

[6]. J. M. O’Mally, A. U. Chamot, “Learning strategies in second language acquisition”, Cambridge University Press, Cambridge, 1990.

[7]. R. L. Oxford, "Language learning strategies: what every teacher should know”, Newbury House/Harper Collins, NY, 1990. 